\title{
The external contributory factors for maternal health care in Anuradhapura and Polonnruwa Districts 2008-2010
}

\section{TRN Fernando}

Department of Obstetrics and Gynaecology,

Faculty of Medicine and Allied Sciences Rajarata University of Sri Lanka.

Abstract

Introduction: Maternal mortality ratio (MMR) in Sri Lanka has decreased from 405 per 100,000 live births in 1955 to 39.3 per 100,000 live births in 2006. Family Health Bureau (FHB) statistics indicate there is a large inter-district disparity of MMR in Sri Lanka

Objectives: To compare the external contributory factors leading to maternal mortality and morbidity in the districts of Anuradhapura \&Polonnaruwa. And, also to compare the availability of staff in maternal care in the above 2 districts.

Method: A retrospective analysis of data collected from the RDHS offices and hospital statistics units of Anuradhapura \&Polonnaruwa districts, regarding the health care personnel \& MMR in each district in 2008-2010.

Study was carried out from March to May 2011.

Results: Number of pregnant mothers per PHM was higher in Anuradhapura district (AD) compared to Polnnaruwa district (PD). Number of deliveries per each midwife was higher in Anuradhapura teaching hospital (ATH) compared to Plonnaruwa General hospital (PGH). Available health care staff in obstetric wards in ATH is low compared to PGH. The MMR was better in AD compared to PD in the years of 2008-2010.
Conclusion: Human resources have been unequally distributed among the 2 districts in the years 20082010. As a result ATH is burdened with a heavy work load. Yet the MMR in AD in 2008-2010 was lower than PD.

\section{Introduction}

At first glance, Sri Lanka would appear to be poorly equipped to commit to maternal health care. The country has faced years of internal conflict, and more than one-third of Sri Lankans live below the poverty line. Yet providing health care to women in clinics and hospitals, and in their homes, has resulted in the reduction of the country's maternal mortality rate by $87 \%$ in the past 40 years.

Maternal mortality ratio (MMR) in Sri Lanka has decreased from 405 per 100,000 live births in 1955 to 39.3 per 100,000 live births in 2006 (figure 1).It is reported that $72-75 \%$ of these maternal deaths are preventable, and in most cases correctable conditions were not detected until the woman has become pregnant, while some conditions were detected only during delivery ${ }^{1}$. Also Family Health Bureau(FHB) statistics indicate there is a large interdistrict disparity of MMR in Sri Lanka (figure 2). 


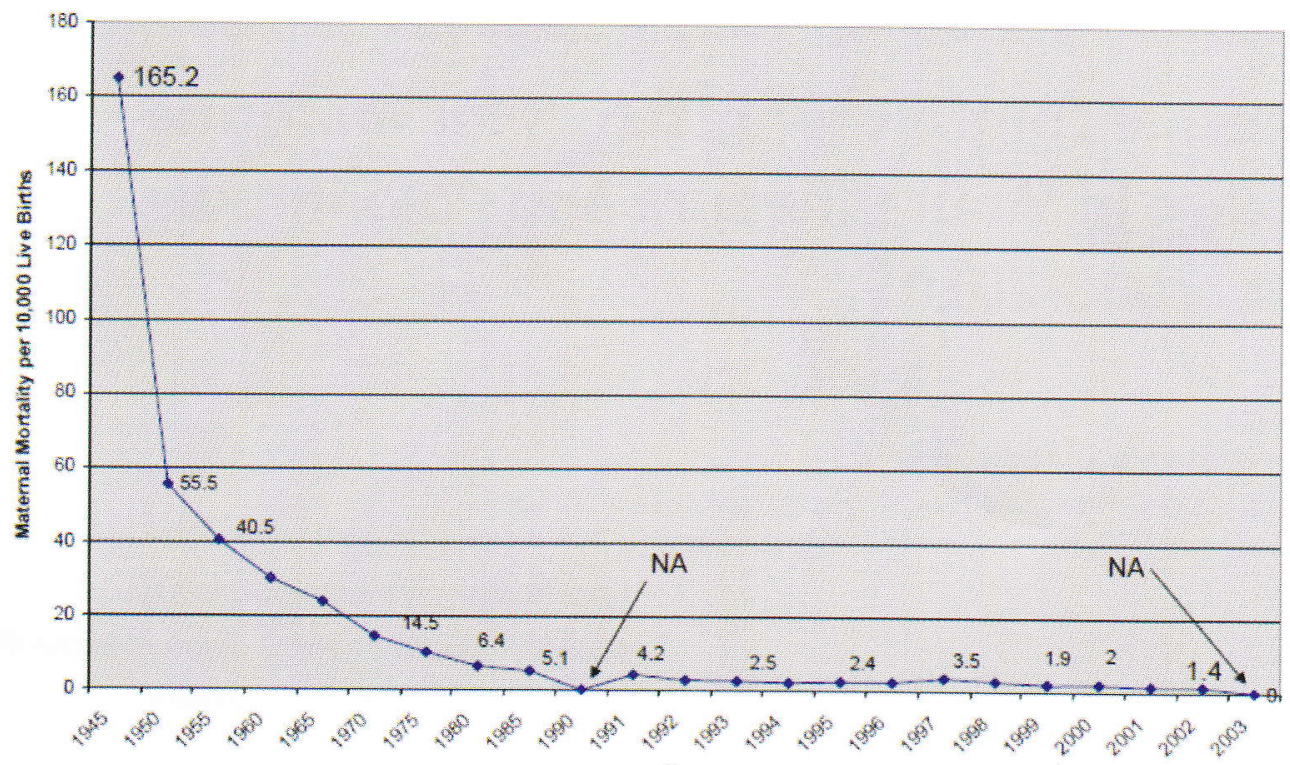

Figure 1: MMR per 10,000 live births from 1945-2003in Sri Lanka

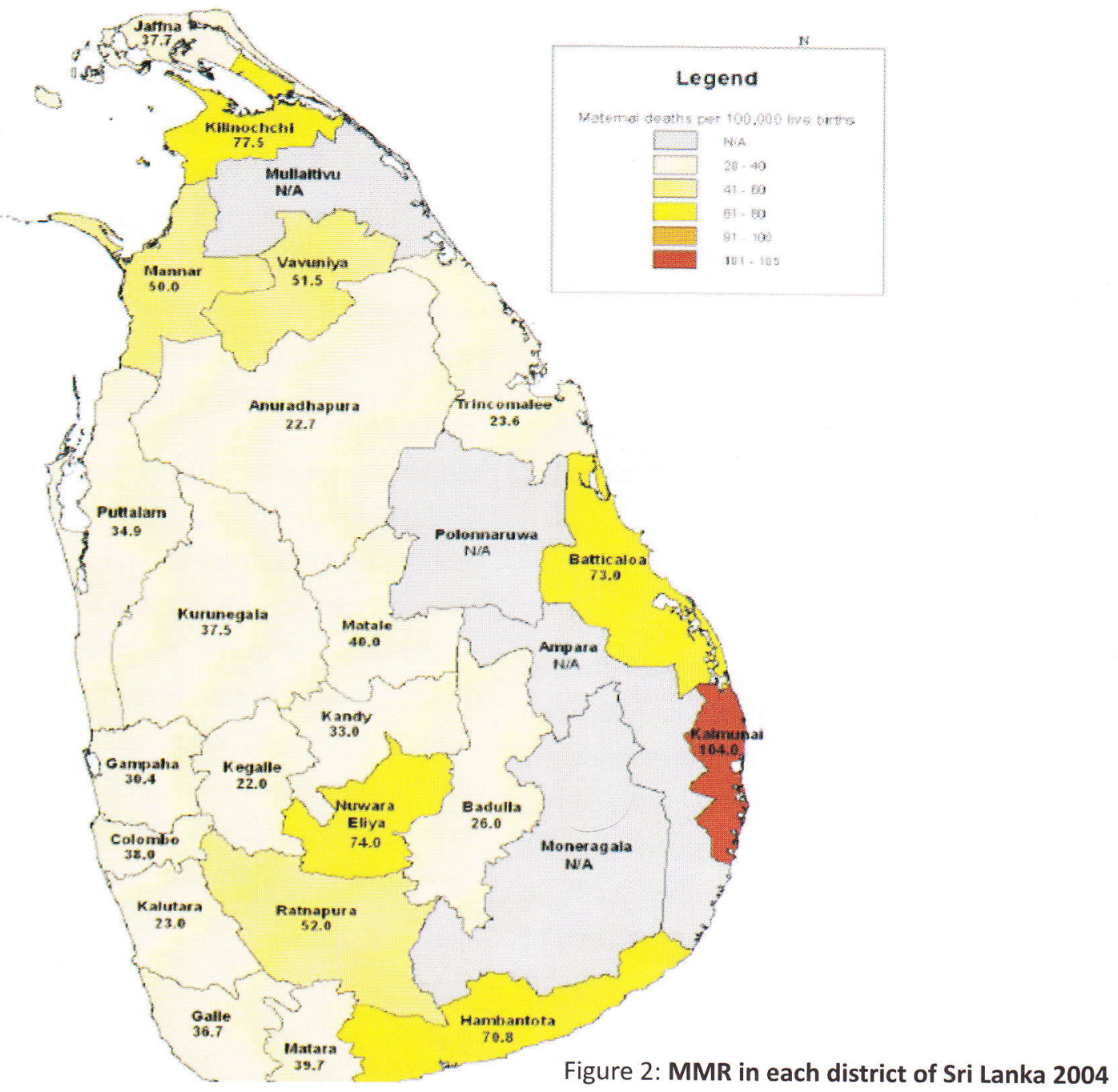




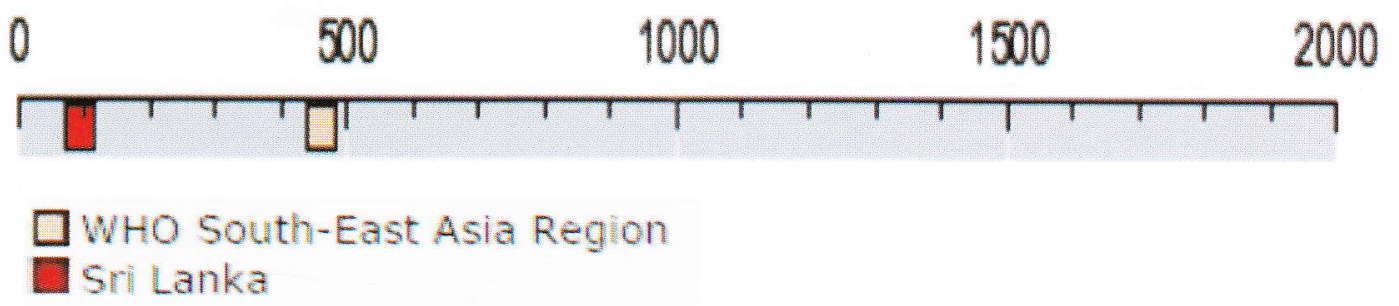

Figure 3 MMR in Sri Lanka compared to South East Asia, 2006 WHO country report

Sri Lanka has one of the best MMR in south East Asia region. India's maternal mortality rate stands at 450 per 100,000 live births \& in Pakistan MMR is 260 per 100,000 live births in 2008 (WHO country report).

\section{Methodology}

Data collection was carried out among registered pregnant mothers in the north central province (NCP) from 2008 to 2010.
Data collected from the RDHS offices and hospital statistics units of Anuradhapura \& Polonnaruwa districts, regarding the health care personnel \& MMR in each district in 2008-2010.

Study was carried out from March to May 2011.

\section{Results}

\begin{tabular}{|c|c|c|}
\hline Year & Anuradhapuradistrict & Polonnaruwadistrict \\
\hline 2008 & 74 & 69 \\
\hline 2009 & 73 & 64 \\
\hline 2010 & 76 & 61 \\
\hline
\end{tabular}

Table 1.Eligible families per public health midwife (PHM)

\begin{tabular}{|c|c|c|}
\hline Year & Anuradhapura district & Polonnaruwa district \\
\hline 2008 & 2463 & 572 \\
\hline 2009 & 637 & 512 \\
\hline 2010 & 640 & 512 \\
\hline
\end{tabular}

Table 2.Number of pregnant mothers per PHM

\begin{tabular}{|c|c|c|}
\hline Year & $\begin{array}{c}\text { Anuradhapura teaching } \\
\text { hospital (ATH) }\end{array}$ & $\begin{array}{c}\text { Polonnaruwa general } \\
\text { hospital (PGH) + BH }\end{array}$ \\
\hline $\mathbf{2 0 0 8}$ & $\mathbf{1 1 8 7}$ & $\mathbf{2 3 0}$ \\
\hline 2009 & 1186 & 299 \\
\hline 2010 & 1547 & 237 \\
\hline
\end{tabular}

Table 3.Number of deliveries per each midwife 


\begin{tabular}{|c|c|c|}
\hline Year & ATH & PGH + BH \\
\hline 2008 & 7714 & 2071 \\
\hline 2009 & 7709 & 2687 \\
\hline 2010 & 7734 & 2135 \\
\hline
\end{tabular}

Table 4.Number of pregnant mothers per VOG

\begin{tabular}{|l|c|c|c|c|c|c|}
\hline \multirow{2}{*}{ Staff } & \multicolumn{3}{c|}{ Anuradhapura (ATH) } & \multicolumn{3}{c|}{ Polonnaruwa (GH, BH) } \\
\cline { 2 - 7 } Number of VOGs & 2008 & 2009 & 2010 & 2008 & 2009 & 2010 \\
\hline Number of Doctors & 2 & 2 & 2 & 3 & 3 & 3 \\
\hline Number of Nurses & 10 & 10 & 10 & 11 & 12 & 13 \\
\hline Number of Midwifes & 12 & 12 & 15 & 23 & 23 & 23 \\
\hline Number of Minor staff & 13 & 13 & 10 & 27 & 27 & 27 \\
\hline Number of obstetric wards & 2 & 8 & 7 & 10 & 10 & 10 \\
\hline
\end{tabular}

Table 5.Available health care staff in ATH, PGH \& PollonnaruwaBH in obstetrics wards

\begin{tabular}{|c|c|c|}
\hline Year & $\begin{array}{c}\text { Anuradhapura (ATH) } \\
\text { Polonnaruwa } \\
\text { (GH \&BH) }\end{array}$ \\
\hline 2008 & 1543 & 565 \\
\hline 2009 & 1542 & 672 \\
\hline 2010 & 1547 & 493 \\
\hline
\end{tabular}

Table 6.Total deliveries per doctor

\begin{tabular}{|c|c|c|}
\hline Year & Anuradhapura district & Polonnaruwa district \\
\hline 2008 & 51 & 56 \\
\hline 2009 & 62 & 97 \\
\hline 2010 & 65 & 76 \\
\hline
\end{tabular}

Table 7.Total maternal deaths per 100,000 pregnancies 


\begin{tabular}{|l|c|c|c|}
\hline \multicolumn{1}{|c|}{ BH } & Distance from ATH & $\begin{array}{c}\text { Admissions per } \\
\text { month }\end{array}$ & $\begin{array}{c}\text { \% of transfers to } \\
\text { ATH }\end{array}$ \\
\hline Padaviya & $82 \mathrm{Km}$ & 71 & $40 \%(28 / 71)$ \\
\hline Kebithigollewa & $82 \mathrm{Km}$ & 72 & $71 \%(51 / 72)$ \\
\hline Thmbuttegama & $37 \mathrm{Km}$ & 78 & $35 \%(27 / 78)$ \\
\hline
\end{tabular}

Table 8.comparison of admissions to and transfers from maternity wards in $\mathrm{BH}$ in Anuradhapura districts

\section{Discussion}

Anuradhapura teaching hospital (ATH) is the main hospital providing specialists obstetric care, in Anuradhapura district, until the end of 2010 . 98\% of all deliveries of Anuradhapura district are done at

$\mathrm{ATH}^{5}$. The drainage area of the district is the largest in Sri Lanka.

Tables $1,2,3,4 \& 5$ indicates that patient staff ratio is higher in Anurdhapura district compared to pollonnaruwa district. Number of eligible families per PHM \& number of pregnant mothers per PHM were higher in Anurdhapura district (table $1 \& 2$ ). As per table 3number of deliveries per each midwife is 1547 in ATH compared to 237 PGH in the year 2010. This highlights the increased work load at ATH to midwives. This is the same when comparing patient doctor ratio and consultant (VOG) patient ratios in all three years.

There are 3 designated base hospitals (BH) in Anuradhapura district. They are Padaviya, Kebithigollewa and Thmbuttegama base hospitals. Located $82 \mathrm{Km}, 67 \mathrm{Km} \& 37 \mathrm{Km}$ distance, respectively from the ATH. Only Thambuthegama base hospital has one consultant obstetrician and a paediatrician (appointed in 2011), while the other 2 base hospitals lack specialists services in maternal \& child health (untilMay 2011). These BHs are understaffed and under resourced to carry out specialised maternal care at the time of this study. Many women are transferred to ATH for delivery.
Statistics in January to May 2011, indicates that the average admission to maternity ward was 73 mothers per month in all $3 \mathrm{BHs}$. Out of these admissions 40\% from PadaviyaBH \& 71\% from Kebethigollewa $\mathrm{BH}$, were transferred to ATH.There were only $35 \%$ transferresfrom Thambutthegama BH for maternity care (table 8).

Polonnaruwa district which is smaller in sizecompared to Anuradhapura, has one base hospital at Madirigiriya $30 \mathrm{Km}$ away from the general hospital Polonnaruwa. The drainage area is smaller and the population is less too,compared to Anuradhapura district ${ }^{6}$.

\section{Conclusion}

From the above data we can infer that the human resources have been unequally distributed among the 2 districts and as a result ATH is burdened with a heavy work load. However the MMR is comparatively less in Anuradhapura district (table 7). There is an increasing trend of MMR form 20082010 in both districts. If the staff patient ratio is improved there would be better out come in maternal care at ATH.

There is a huge fluctuation in Polonnaruwa district's MMR during these 3 years. A separate research should be done to find out the underlying causes for this trend in Polonnaruwa district. Also why the MMR is high in polonnaruwa district when patient staff ratio is low compared to Anuradhapura district. 


\section{Referrances:}

1. FHB - Annual Report on Family Health -2006/07

2. UNICEF. Prioritizing maternal health in Sri Lanka.http://www.unicef.org/devpro/46000_4 8498.html

3. www.statistics.gov.lk

4. Rodrigo JN, Fernando L, et al, 1996, Maternal Deaths in Sri Lanka A Review of Estimates and Causes.

5. Family Health Bureau, 2007, Medium Term Plan on Family Health.

6. Medical Statistics Unit, Department of Health, 2007, Annual Health Statistics Sri Lanka.

\section{Aknowlegdements:}

1. Medical students of batch 2005-06 for helping in data collection.

2. MaliniUdupihille, Dean, Faculty of Medicine and Allied Science (FMAS), RUSL.

3. Prof. Nugegoda, acting Head, Dept of community medicine, FMAS, RUSL.

4. Dr.Wijekoon, director, ATH

5. RDHS office Anuradhapura \&Polonnaruwa districts.

6. General hospital Polonnaruwa statistics unit

7. Base hospitalsThambuttegama, Kebathigollewa \& Padaviya Staff.

8. Dr.B.G.S.Jayaratna, Temporary Lecture, Obstetrics and Gynecology Department, FMAS.

9. Dr.E.C.K.Lankeshwara, Temporary Lecture, Obstetrics and Gynecology Department,FMAS.

\section{Author}

- Mrs. TRN Fernando

Lecturer, Department of Obstetrics and Gynecology, Faculty of Medicine and Allied Sciences,

Rajarata University of Sri Lanka. 